\title{
In planta test system for targeted cellular mutagenesis by injection of oligonucleotides to apical meristem of maize seedlings
}

\author{
Feríz Rádi ${ }^{1,2,3} \cdot$ Bettina Nagy $^{1,7} \cdot$ Györgyi Ferenc ${ }^{1}$ (1) $\cdot$ Katalin Török $^{1} \cdot$ István Nagy ${ }^{4,5} \cdot$ Zoltán Zombori $^{1}$. \\ Dénes Dudits ${ }^{1,2} \cdot$ Ferhan Ayaydin $^{6,7}$
}

Received: 31 March 2020 / Revised: 23 March 2021 / Accepted: 19 April 2021 / Published online: 29 April 2021

(c) The Author(s) 2021

\begin{abstract}
Genome-editing tools from Oligonucleotide-Directed Mutagenesis (ODM) to CRISPR system use synthetic oligonucleotides for targeted exchange of nucleotides. Presently, majority of genome-editing protocols are dependent on the in vitro cell or tissue culture systems with somaclonal variation, and limitations in plant regeneration. Therefore, here, we report an alternative in planta cellular test system for optimization of the ODM, based on the injection of oligonucleotide solution into the apical meristematic region of haploid maize seedlings. Using 5'-fluorescein-labeled oligonucleotides, we detected accumulation of synthetic DNA molecules in cells of the shoot apical meristem and of the vascular bundles of leaf primordia. For silencing or knocking down of the phytoene desaturase gene in somatic cells, 41-mer long single-stranded oligonucleotides with TAG stop codon were injected into maize seedlings. We detected out-growing M1 plantlets that developed leaves with white stripes or pale-green color. Confocal microscopy of white stripes showed that in addition to the chlorophyll fluorescence-deficient tissue region, chlorophyll containing cells are present in white stripes. The Ion Torrent sequencing of DNA samples from the white stripes indicated $0.13-1.50 \%$ read frequency for the TAG stop codon in the phytoene desaturase gene. Appearance of chlorotic abnormalities supports the mutagenic nature of oligonucleotide molecules after injection into the shoot apical meristem region of maize seedling. The described protocol provides basis for early seedling stage characterization of functionality of a mutagenic oligonucleotide with different chemistry and testing efficiency of various treatment combinations at plant level.
\end{abstract}

Keywords Chlorotic mutant $\cdot$ Maize $\cdot$ Oligonucleotide-directed mutagenesis (ODM) $\cdot$ Phytoene desaturase gene $\cdot$ Shoot meristem $\cdot$ Test system $\cdot$ In planta

\section{Introduction}

Current genome-editing technologies including the most preferred CRISPR/Cas9 system introduce double-stranded (ds) DNA breaks by nuclease enzymes at a target locus in plant genomes (Jaganathan et al. 2018). Alternatively, editing of plant genes via generation of single base mutation was successfully achieved by introducing single-stranded DNA oligonucleotides (SDOs) into plant cells or protoplasts and regeneration of mutant plants (Rivera-Torres and Kmiec

Communicated by P. Wojtaszek.

Feríz Rádi and Bettina Nagy contributed equally to this work.

Györgyi Ferenc

ferenc.gyorgyi@brc.hu

Extended author information available on the last page of the article
2016; Sauer et al. 2016). The oligonucleotide-directed mutagenesis $(\mathrm{ODM})$ and the use of programmable nucleases represent alternative as well as complementary approaches with different molecular mechanisms (Gocal 2015). The template-directed repair of double-stranded breaks in the presence of exogenously supplied SDOs was also tested in plant systems (Svitashev et al. 2015; Wang et al. 2015; Sauer et al. 2016).

In practice, for ODM, the chemically synthesized oligonucleotide molecules are introduced into plant protoplasts, cells, embryo-derived callus tissues cultured in vitro. Most frequently, SDO molecules are precipitated onto gold microprojectiles and bombarded into cultured cells. As pioneering work, Beetham et al. (1999) bombarded cells from tobacco suspension culture with chimeric oligonucleotides composed of DNA and modified RNA residues and the mutated acetolactate synthase gene imparted chlorsulfuron resistance. 
In maize, both immature embryo-derived callus tissues and cultured cells were bombarded with synthetic SDOs. Plant protoplasts as membrane surrounded cells can serve as recipient for SDO molecules. Either PEG-mediated uptake or electroporation was successfully used for oligonucleotide delivery into tobacco, oilseed rape, and Arabidopsis protoplasts (Kochevenko and Willmitzer 2003; Ruiter et al. 2003; Kim and Kim 2014; Gocal 2015).

Thus far, the reported methodologies for ODM are based on different tissue culture techniques that ensure fertile plant regeneration from the mutated cells cultured in vitro. Since the morphogenic or embryogenic potentials of dedifferentiated callus tissues are highly dependent on the genotype also in maize (Armstrong et al. 1991), this component in editing protocols can limit wider use of ODM as a new breeding technique. Therefore, in attempts to extend the application of this technology, various in planta-editing protocols may gain preference.

Uptake of SDO molecules into cells of plant organs and their functionality were primarily studied using antisense oligonucleotides. There are several reports about the uptake of these molecules into intact plant tissues such as leaves (Sun et al. 2005; Dinc et al. 2011), fast-growing pollen tubes (Liao et al. 2013) or whole plants (Xie et al. 2014). One candidate for ODM treatment can be the shoot apical meristem (SAM) that was extensively used explant for transformation protocols (Sticklen and Oraby 2005; Baskaran and Dasgupta 2012; Baskaran et al. 2016).

As an initial step, here, we report a test system for ODM in somatic haploid cells of maize seedlings. Albino marker mutations were induced in shoot apical meristem region of the seedlings by injection of premature STOP codon-bearing synthetic oligonucleotides that are homologous to the phytoene desaturase gene. Development of leaves with white stripes or reduced fluorescence signal in pale-green leaves served as phenotypic indication for the functionality of mutagenic SDOs. Statistical analysis of NGS datasets confirmed specific mutation events. The experimental approach described here opens a way for functional characterization of synthetic oligonucleotides with chemical modifications or optimizing cellular stage by modification of chromatin structure (Tiricz et al. 2018).

\section{Materials and methods}

\section{Growth and treatment conditions of maize haploid seedlings}

For the present test system's development, we used haploid maize genotype produced by crossings between the maize haploid inducer line and the female parent. The marker system using the R1-nj allele of the $\mathrm{r} 1$ gene locus allowed visual separation of haploids and diploids by seed phenotyping of anthocyanin coloration. The maternal haploid progenies showed purple pigmentation in the endosperm tissue on the crown of the kernel and colorless embryos. At the whole plant level, the haploid genome size was confirmed by the flow cytometry of nuclei isolated from leaves as described before (Tiricz et al. 2018).

Haploid kernels were germinated in wet and rolled filter paper aligned vertically in $3 \mathrm{~L}$ beaker filled with $0.5 \mathrm{~L}$ tap water. The germinated haploid seedlings reached about $2 \mathrm{~cm}$ long coleoptile size after 6 days in $16 \mathrm{~h}$ light $/ 8 \mathrm{~h}$ dark at $24{ }^{\circ} \mathrm{C}$ room temperature. At this stage, they were cut horizontally approximately $1 \mathrm{~cm}$ above the coleoptile-mesocotyl junction, and the meristem region was pierced vertically (through the cut side) with a $27 \mathrm{G}$ needle. The synthetic oligonucleotides representing the target sequence of $P D S$ gene were dissolved in nuclease-free water at $100 \mu \mathrm{M}$ concentration, selected in several test experiments. Oligo solution $(3 \mu \mathrm{L})$ was injected into the meristem region of each plant. These treated seedlings were planted in styrofoam trays containing peat moss and grown in a glasshouse with $16 \mathrm{~h}$ light $/ 8 \mathrm{~h}$ dark at $28{ }^{\circ} \mathrm{C}$ up to maturity.

\section{Design and synthesis of FAM-labeled or mutagenic oligonucleotides}

The 41-mer single-stranded DNA oligonucleotide named SDOPDS (5'-g aaT ATT ACT GGA GCT AGC TAG ACA AGA TCT TTT GCG $g g c$ C-3', lowercase letters stand for phosphorothioates) was designed for creating a STOP codon into maize $P D S$ gene. The oligonucleotide was placed as close to the start codon as possible with the targeted mutation in the middle of the oligonucleotide. To help the synthesis and purification of the SDO, the $G G G G$ quartet was changed to $G G G C$. Finally, the specificity of the $\mathrm{SDO}^{\mathrm{PDS}}$ sequence was checked in maize genome using NCBI blast.

The chemical synthesis of the SDO ${ }^{\mathrm{PDS}}$ molecule was performed using a DNA/RNA/LNA H-16 synthesizer (K\&A Laborgeraete) by standard $\beta$-cyanoethyl phosphoramidite chemistry at a nominal scale of $0.2 \mu \mathrm{mol}$. For oligonucleotide uptake studies, a 40-mer SDOs representing random nonsense sequences were labeled at the $5^{\prime}$-end by fluorescein (6-FAM). SDO ${ }^{\mathrm{PDS}}$ was purified by reverse phase HPLC followed by cation exchange using Dowex 50 resin.

The reagents for automated SDO synthesis and fluorescent labeling were from Link Technologies, Chemgenes, Sigma Aldrich, and Molar Chemicals Kft.

\section{PCR amplification and sequencing of the phytoene desaturase gene}

Genomic DNA from the untreated control and the SDOtreated maize plant's leaves with phenotypic symptoms were 
isolated with a CTAB-based extraction method according to Doyle (1990).

For analysis of the oligonucleotide-targeted nucleotide exchange, PCR amplifications were performed with the following phytoene desaturase gene-specific primers: ZmPDS_Forward: 5'-CAGTAGTCTGCCTGTACCTATTG3', ZmPDS Reverse: 5'-CGGTGTGATCTCCTTCCTTTAT$3^{\prime}$ ) with Ion P1 and different barcode adaptors. Phusion Hot Start II High Fidelity DNA Polymerase (Thermo Scientific) was used for the PCR reactions with the following cycle conditions: 1 . Initial denaturation: $98^{\circ} \mathrm{C}$ for $3 \mathrm{~min}$. 2. Denaturation: $98{ }^{\circ} \mathrm{C}$ for 30 s. 3 . Annealing: $63{ }^{\circ} \mathrm{C}$ for 45 s. 4 . Extension: $72{ }^{\circ} \mathrm{C}$ for 30 s. (2-4 steps: 30 cycles) 5 . Final extension: $72{ }^{\circ} \mathrm{C}$ for $10 \mathrm{~min}$. Amplified fragments were purified by GeneJet Gel Extraction kit (Thermo Scientific) according to the manufacturer's recommendation. Fragments of 312 nucleotides were used for Ion Torrent sequencing, which were performed as described earlier in Tiricz et al. (2018).

\section{Microscopy and imaging}

Fluorescent oligonucleotide-injected apical meristem regions of 6-day-old hand sectioned maize seedlings were imaged using Leica SP5 laser scanning confocal microscope (Leica Microsystems GmbH, Wetzlar, Germany) either by directly layering intact potted plants' leaf over the immersion objective using a coverslip-bottom Petri dish (Fodor and Ayaydin 2018) or by excision of the leaf and mounting on $24 \times 50 \mathrm{~mm}$ coverslip. For chlorophyll imaging, $543-\mathrm{nm}$ laser and a detection range of $650-750 \mathrm{~nm}$ were used. For cell wall autofluorescence, 405-nm laser excitation and 415-530-nm emission range were used. Macroscopic leaf images were captured using Samsung Galaxy Note 8 mobile phone camera (Samsung Electronics, Seoul, South Korea). Plot profile measurement of selected rectangular areas was performed using Fiji software (Schindelin et al. 2012). Exported intensity values of plot profiles were used to plot the charts in Microsoft Excel 2010 (Microsoft, Redmond, WA, USA). Composite images were prepared using CorelDraw Graphics Suite X7 (Corel Corporation, Ottawa, Canada).

\section{Results and discussion}

\section{Detection of FAM-labeled oligonucleotides in maize meristematic tissues after injection into the basal region of seedling}

To monitor the uptake and tissue distribution of SDO molecules injected into the basal section of seedlings, 40-mer SDOs nonsense sequences were synthesized with covalently attached 5'-fluorescein (6-FAM representing random) dye. The localization of these molecules was analyzed by confocal laser scanning microscopy. In the longitudinal sections of seedlings after $24 \mathrm{~h}$ of injection, the green fluorescence intensity was high in shoot apical meristem and vascular bundles of leaf primordia (Fig. 1a, c). Close-up imaging of the meristem region showed fluorescent material to be accumulated inside and around the cells (Fig. 1d, e with arrowheads). Lack of green fluorescence in water-injected control samples indicated that the observed green fluorescence of injected samples was not due to artifactual wounding-induced autofluorescence (Fig. 1b).

Experimental evidence for introducing synthetic oligonucleotide molecules into the tissues and cells of different plant organs are only known from studies with antisense oligonucleotides (asSDOs). These molecules could be infiltrated in intact tobacco leaves with the help of a syringe or by vacuum treatment (Dinc et al. 2011; Wojtasik et al. 2014). The wheat leaves were cut, and the lower $1-$ to $2 \mathrm{~cm}$ part was submerged in asSDO water solution. For the present ODM treatment, we target maize shoot apical meristem at an early developmental stage of seedlings. Cereal shoot apical meristems were widely used for different genetic transformation protocols including Agrobacterium infection or microinjection of the shoot apical meristem explants (reviewed in (Sticklen and Oraby 2005). Cells of the L2 layers of isolated shoot meristems from maize were microinjected with vector constructs for anthocyanin production (Lusardi et al. 1994). In the present study, the high-resolution confocal laser scanning microscopy showed that the SDO molecules could be accumulated in meristematic cells (Fig. 1).

\section{Chlorotic phenotypes of leaves from the outgrowing M1 haploid maize plants}

The primary goal of the present study was to establish a gene-specific mutagenesis test system by injection of synthetic plus-strand SDO molecule solution into the meristematic region of young maize seedlings. For phenotypic monitoring of mutagenic events in haploid somatic cells, we selected the phytoene desaturase (ZmPDS) gene, encoding a key enzyme in carotenoid biosynthesis, and that was widely used in genome-editing experiments with CRISPR/Cas9 system (Jia and Wang 2014; Wang et al. 2015; Nishitani et al. 2016; Odipio et al. 2017). T-DNA insertion mutant of Arabidopsis PDS3 gene showed dwarfism and albino phenotypes due to impairment in chlorophyll, carotenoid, and gibberellin biosynthesis (Qin et al. 2007). For functionality test of SDO molecules, we used haploid maize seedlings to detect mutation events by appearance of chlorotic phenotype in the SDO-treated M1 generation plants. After crossing with the maize haploid inducer line, haploid kernels were selected on the basis of the anthocyanin pigmentation encoded by the 

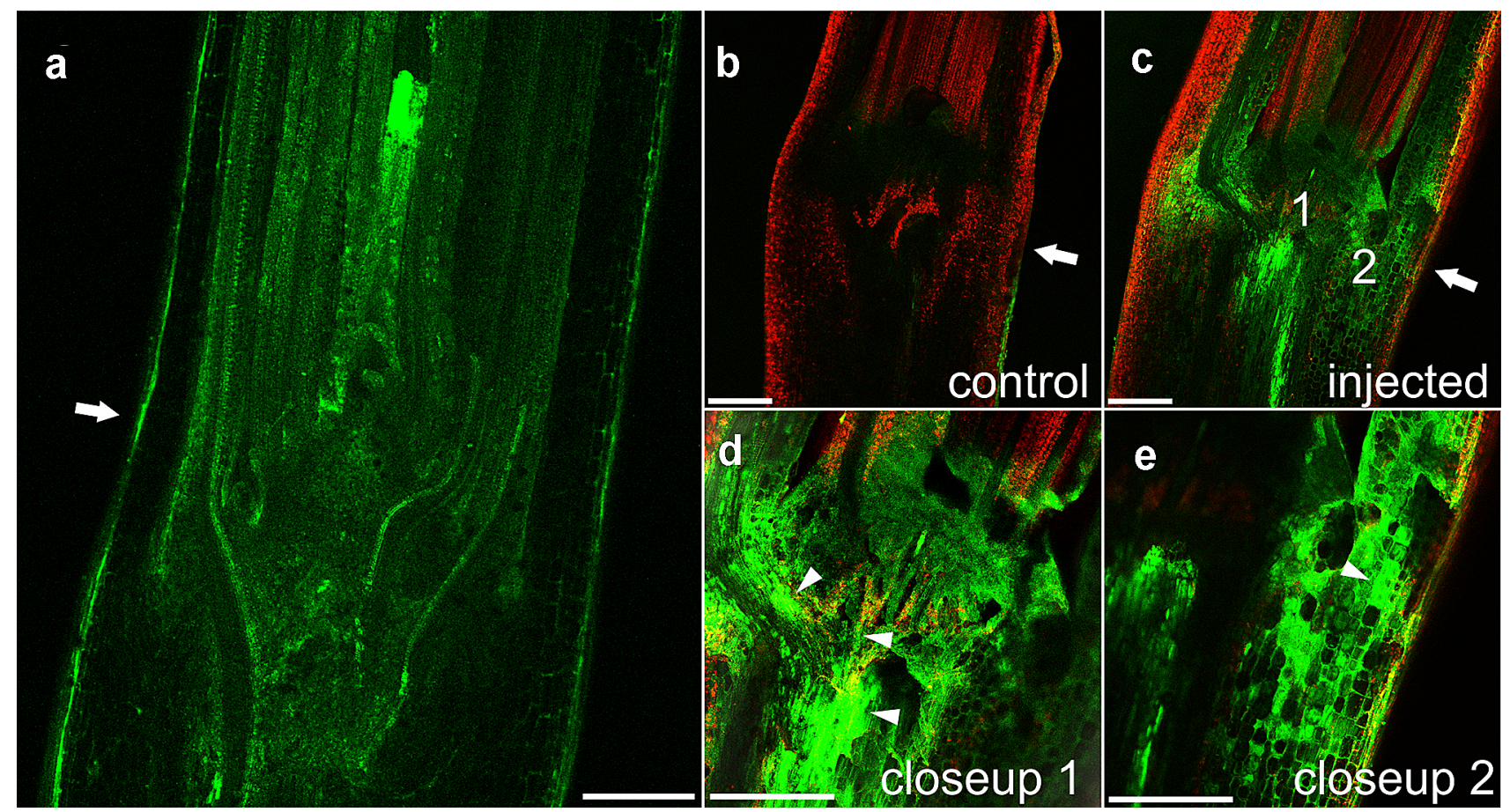

Fig. 1 Tissue distribution of fluorescein-labeled oligonucleotides in shoot meristem of maize seedling after the injection. a and c Low magnification imaging of cross-sections showing higher green fluorescence intensity in the oligonucleotide-injected region and in shoot apical meristem. Arrows point to the approximate position of shoot apical meristem. b Water-injected control sample. d and e Higher

$R 1-n j$ gene. The haploid nature of treated plants was confirmed at a later developmental stage by isolation of nuclei from leaves, and identification of genome size with flow cytometry (Rádi et al. 2020).

For designing and synthesis of mutagenic SDO molecules, $Z m P D S$ gene was sequenced from the recipient maize genotype. According to the BLAST search in Phytozome database, this gene is located on chromosome 1 (LOC542329). In addition, the truncated 15-cis phytoene desaturase gene (LOC103633372) is located on chromosome 7. Therefore, targeted mutagenesis of $\mathrm{ZmPDS}$ gene in haploid maize plants can serve as a test system with phenotypic marker. After identification of the target region, the 41 nucleotide- long molecule was synthesized with TAG stop codon (Table 1a). Out of 90 treated plants, 4 of them developed leaves with different patterns of white or pale-green stripe (Fig. 2c,d) and 1 plant developed pale-green leaves (Fig. 2b). M1 plant with white stripes located on different leaves could also been identified (Fig. 2f). One of these leaves showed two mutant cell lineages represented by the parallel white stripes (Fig. 2g). Quantification of fluorescence signal intensities in a rectangular selection area revealed average pixel intensity values of 111.8 and 52.4 for wild-type and pale-green mutant leaf, respectively (Fig. 3a,c). Moreover, we could recognize cells with high signal intensity in mutant magnification confocal microscopy images captured from the sample shown in (c). The numbers 1 and 2 are placed to indicate the regions from which the close-up images were prepared. Arrowheads highlight some of the oligonucleotide-accumulated regions. Chlorophyll autofluorescence of samples are displayed in red for panels $(\mathbf{b}-\mathbf{e})$. Scale bars: $500 \mu \mathrm{m}$

leaf, as well. This pattern suggests a chimeric nature of palegreen leaf with mixture of wild-type and mutant cells. Confocal microscopy of white leaf stripe revealed both chlorophyll fluorescence minus and plus cells with dominant presence of albino cells (Fig. 3d,f). The appearance of white stripes in green leaf tissues can be an indication for the targeted mutagenic function of SDO molecules, resulting in a limited number of mutation events in dividing cells of leaf primordia. Dry maize seeds can contain four to five embryonic leaves that are activated during germination (Liua and Chang 2013). Uptake of mutagenic SDO molecules into cells of early leaf primordia (Fig. 1e) can be a starting point for initiation of albino stripe. Mutant phenotypes detected here show a close similarity with maize plants edited in phytoene synthase gene by CRISPR/Cas9 system (Zhu et al. 2016). An early study by Lusardi et al. (1994) can help to interpret the observed pattern of mutant tissue regions. These authors microinjected five individual cells of the L2 layer in isolated maize shoot apical meristems with transformation vectors expressing the Lc gene of anthocyanin biosynthesis. The cells showing anthocyanin accumulation were organized in sectors consisting of a stripe located along the vein, with a length ranging between 0.5 and $1.5 \mathrm{~cm}$. In some cases, more than one stripe was visible on the same leaf running parallel along different veins. The complete 
Table 1 Ion torrent sequencing shows targeted nucleotide conversions by injection of synthetic oligonucleotide molecules into the meristematic region of maize seedlings

(a)

Mutagenic oligonucleotide

ZmPDS wild type

Target gene read with TAG

(b)
5'-G AAT ATT ACT GGA GCT AGC TAG ACA AGA TCT TTT GCG GGC C -3'

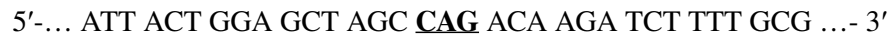

5'-... ATT ACT GGA GCT AGC TAG ACA AGA TCT TTT GCG ...- 3'

Genotype

Target gene reads with $\mathrm{CAG}$

Target gene

reads with

TAG

Wild type

14,904

$5(0.0335 \%)$

Mutant No. 1

29,551

$66(0.223 \%)$

Mutant No. 2

16,172

$21(0.130 \%)$

Mutant No. 3

13,346

$203(1.50 \%)$

Mutant No. 4

30,778

$627(1.20 \%)$

(a) Nucleotide sequence of mutagenic oligonucleotide, wild-type and mutant variant reads of target $Z m P D S$ gene fragment. Critical residues are highlighted (bold and underlined). (b) The total number and frequency of reads with characteristic triplets

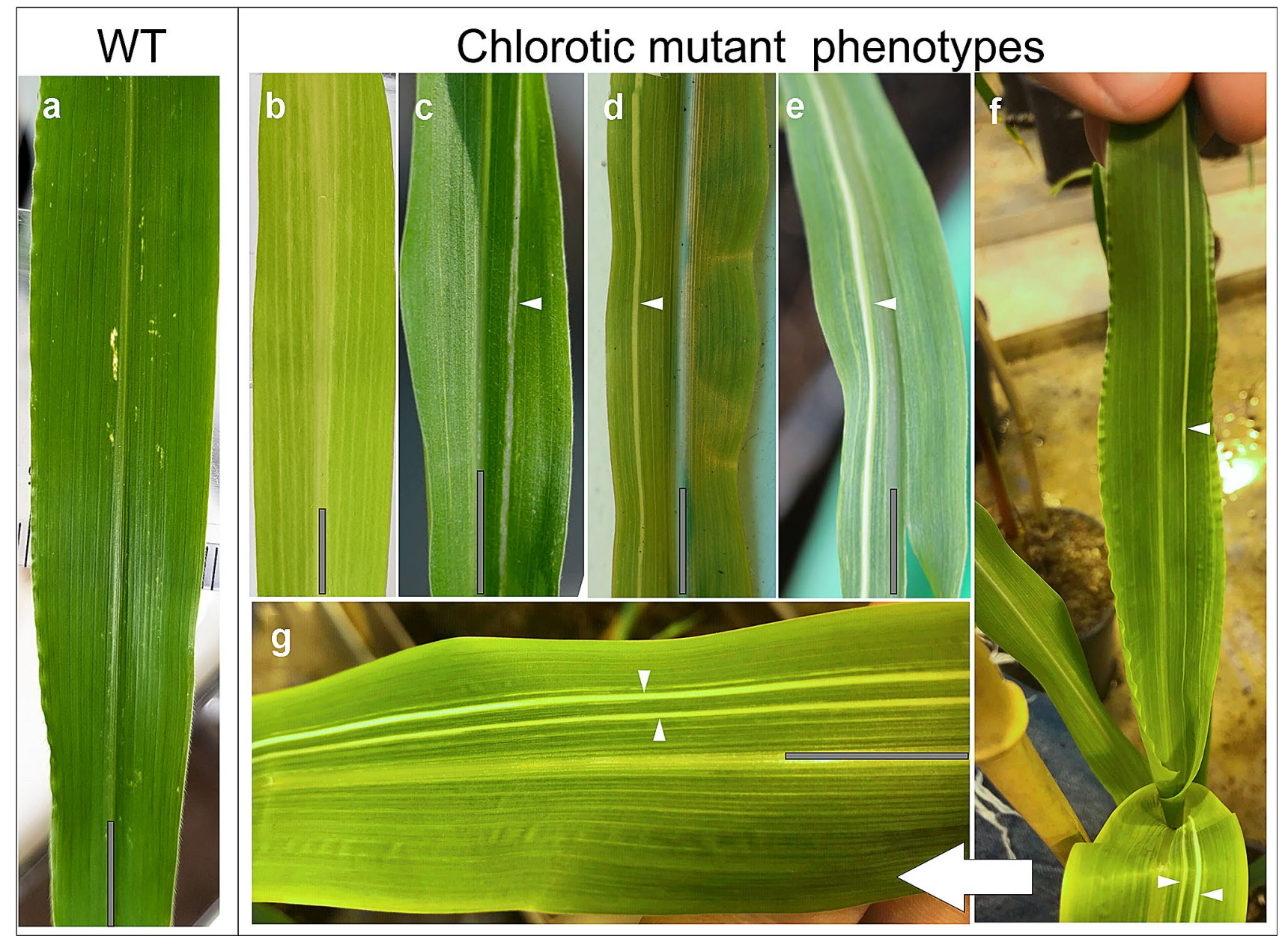

Fig. 2 Variation in the chlorotic phenotype in M1 mutant haploid maize plants after treatment of shoot apical meristem region of seedlings with mutagenic oligonucleotides specific for the phytoene desaturase $(P D S)$ gene. a Wild-type leaf, b pale-green leaf, c leaf with pale stripe, $\mathbf{d}, \mathbf{e}$ leaves with white stripe, $\mathbf{f}, \mathbf{g}$ maize plant with single or doubled white stripes on two different leaves. Arrowheads indicate white stripes. Grey rectangular scale bars $(1 \mathrm{~cm})$ are positioned vertically to mark the position of the mid-veins of the leaves 

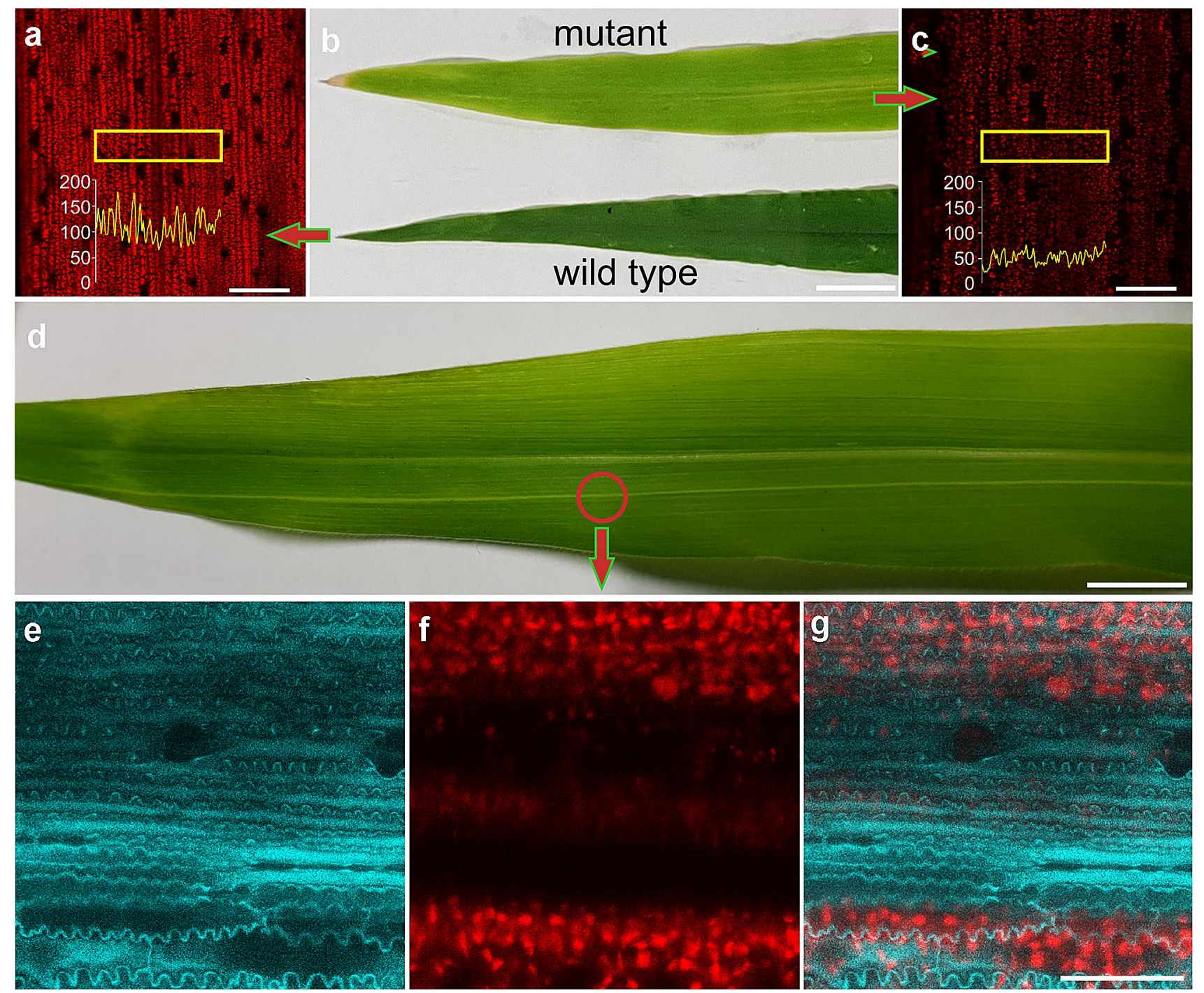

Fig. 3 Reduced chlorophyll fluorescence in leaves after oligonucleotide-directed mutagenesis of the phytoene desaturase $(P D S)$ gene in haploid maize. a, $\mathbf{c}$ Confocal microscopy imaging of parenchyma chlorophyll fluorescence of mutant and wild-type leaf samples shown in panel (b). Intensity profile of a rectangular selection area is shown as image-embedded chart. $Y$-axis represents intensity values (arbitrary units), $x$-axis corresponds to the width of the selected rectan-

pale-green phenotype of several fully developed leaves from one of Zmpds mutants can indicate a different mutation mechanism. Pale-green leaf mutant of Cavendish dessert banana was generated by the CRISPR/Cas9 gene editing of the PDS gene (Naim et al. 2018).

\section{Deep sequencing of PCR amplicons representing the target region of the $Z \mathrm{mPDS}$ gene from the chlorotic leaf sectors}

Selective amplification and sequencing of wild-type and mutagenized ZmPDS genes were used to verify targeted gle. b Macroscopic image of oligonucleotide-treated (pale green) and wild-type leaf. d Formation of white stripe in a leaf of oligonucleotide-treated sample. $\mathbf{e}-\mathbf{g}$ Close-up confocal microscope imaging of cell wall autofluorescence (blue) and chlorophyll autofluorescence (red) of the white stripe shown in panel d. Scale bars: $150 \mu \mathrm{m}(\mathbf{a}, \mathbf{c})$, $1 \mathrm{~cm}(\mathbf{b}, \mathbf{d}), 50 \mu \mathrm{m}(\mathbf{e}-\mathbf{g})$

genome engineering in maize leaf cells by injection of mutagenic oligonucleotide molecules into the meristematic region of seedlings (Table 1). Genomic DNA samples were isolated from the green leaf of an untreated plant and the pale-green leaf of the Zmpds mutant plant, or from the white stripe sectors of mutant leaves. As shown in Table 1a, the wild-type $Z m P D S$ gene in the recipient maize genotype has CAG codon. Here, we used the synthetic oligonucleotides to generate TAG stop codon by $\mathrm{C}$ to $\mathrm{T}$ conversion at the position 236. The Ion Torrent analysis of the amplified PCR fragment from Zmpds mutant tissues revealed 3.94-45.4 times higher number of target reads with TAG than in the 
wild-type $Z m P D S$ gene. The presented frequency data in Table $1 \mathrm{~b}$ are different in various leaf samples of treated seedlings. The presented sequence information shows the occurrence of oligo-directed editing events in some cells of the treated leaf primordium tissues. In these samples, the presence of the wild-type target reads with CAG can be interpreted as a sign of chimeric nature of mature leaves with mixture of wild-type and mutant cells. Treatment of a complex organ, the shoot apical meristem, with SDO molecules generated genetically heterogeneous cell population with a variable frequency of wild-type and mutant cells.

Nucleotide sequencing data presented in Table $1 \mathrm{~b}$ revealed that ODM approach did not induce deletions or insertions in the gene region studied. Preference of specific nucleotide exchange during ODM can be an advantage for this technology in comparison to CRISPR/Cas9 system. As an example, the percentage of deletions ranged from 23.42 to $60.41 \%$ in mutation types induced by CRISPR/Cas9 mutagenesis in maize phytoene synthase gene (Zhu et al. 2016). Genetic diversity represented by functional single nucleotide polymorphisms (SNPs) is a very useful source for trait improvement in plant breeding. The directed conversion of a single nucleotide or the repair of a single base by SDO molecules gain increasing significance in genome editing (Rivera-Torres and Kmiec 2016; Sauer et al. 2016).

In summary, both the detection of chlorophyll content alterations and the Ion Torrent sequencing data support the mutagenic nature of synthetic SDO molecules injected into the meristematic region of maize seedlings. As it is expected, exposition of heterogenic somatic cell population to these synthetic molecules resulted in chimeric shoot apical meristems that could be reflected during subsequent organ development. Despite of this complication, this technology can serve as a test system for functional characterization of SDO molecules in planta. Use of proper marker such as the albino phenotype and haploid seedling allowed recognition of mutant cells or tissue regions in leaves of the M1 generation plant. This approach is far more efficient and faster than editing cultured cells or tissues. Furthermore, in vitro techniques can induce spontaneous mutations, resulting in somaclonal variations (Evans 1989). Indeed, the recent large-scale whole-genome sequencing of rice plants showed that the tissue culture process creates the most offtarget mutations in edited plants (Tang et al. 2018). Further studies are required to test whether the mutated cells of shoot meristems can be involved in sperm cell formation. If this is the case, the induced mutations will be inherited, and the described methodology will have extended applications in plant research.

Author contribution statement Feríz Rádi: conceptualization, methodology, investigation, writing-review and editing. Bettina Nagy: investigation, data curation, writing-review and editing. Györgyi Ferenc: investigation, data curation, supervision, writing-review and editing. Katalin Török: investigation. István Nagy: Data curation, writing-review and editing. Zoltán Zombori: investigation. Dénes Dudits: conceptualization, supervision, writing - original draft. Ferhan Ayaydin: microscopy and image analysis, supervision, writing—review and editing.

Acknowledgements This work was supported by the National Research, Development and Innovation Office, NKFIH (Grant no. K116318). FA has received funding from the EU's Horizon 2020 research and innovation program under grant agreement No. 739593. Very special thanks to T. Kukli and A. Molnár for technical assistance in oligonucleotide synthesis.

Funding Open access funding provided by ELKH Biological Research Center.

\section{Declarations}

Conflict of interest The authors declare that there is no conflict of interest regarding the publication of this paper.

Open Access This article is licensed under a Creative Commons Attribution 4.0 International License, which permits use, sharing, adaptation, distribution and reproduction in any medium or format, as long as you give appropriate credit to the original author(s) and the source, provide a link to the Creative Commons licence, and indicate if changes were made. The images or other third party material in this article are included in the article's Creative Commons licence, unless indicated otherwise in a credit line to the material. If material is not included in the article's Creative Commons licence and your intended use is not permitted by statutory regulation or exceeds the permitted use, you will need to obtain permission directly from the copyright holder. To view a copy of this licence, visit http://creativecommons.org/licenses/by/4.0/.

\section{References}

Armstrong CL, Green CE, Phillips RL (1991) Development and availability of germplasm with high type II culture formation response. Maize Genet Coop Newsl 65:92-93

Baskaran P, Dasgupta I (2012) Gene delivery using microinjection of agrobacterium to embryonic shoot apical meristem of elite indica rice cultivars. J Plant Biochem Biotechnol 21:268-274

Baskaran P, Soos V, Balazs E, Van Staden J (2016) Shoot apical meristem injection: a novel and efficient method to obtain transformed cucumber plants. South Afr J Bot 103:210-215

Beetham PR, Kipp PB, Sawycky XL, Arntzen CJ, May GD (1999) A tool for functional plant genomics: chimeric RNA/DNA oligonucleotides cause in vivo gene-specific mutations. Proc Natl Acad Sci USA 96:8774-8778

Dinc E, Toth SZ, Schansker G, Ayaydin F, Kovacs L, Dudits D, Garab G, Bottka S (2011) Synthetic antisense oligodeoxynucleotides to transiently suppress different nucleus- and chloroplast-encoded proteins of higher plant chloroplasts. Plant Physiol 157:1628-1641

Doyle JJ (1990) Isolation of plant DNA from fresh tissue. Focus $12: 13-15$ 
Evans DA (1989) Somaclonal variation-genetic-basis and breeding applications. Trends Genet 5:46-50

Fodor E. and Ayaydin F. 2018. Fluorescent probes and live imaging of plant cells. In A.M. Sánchez-Moreiras and M.J. Reigosa (eds.), Advances in plant ecophysiology techniques. Springer International Publishing, Cham

Gocal, G.F. 2015. Non-Transgenic trait development in crop plants using oligo-directed mutagenesis : cibus rapid trait development system. In: NABC Report 26 new DNA-editing approaches methods, applications and policy for agriculture (North American Agricultural Biotechnology Council Report)

Jaganathan D, Ramasamy K, Sellamuthu G, Jayabalan S, Venkataraman G (2018) CRISPR for crop improvement: an update review. Front Plant Sci 9:985

Jia HG, Wang N (2014) Targeted genome editing of sweet orange using Cas9/sgRNA. PLoS ONE 9:e93806

Kim H, Kim JS (2014) A guide to genome engineering with programmable nucleases. Nat Rev Genet 15:321-334

Kochevenko A, Willmitzer L (2003) Chimeric RNA/DNA oligonucleotide-based site-specific modification of the tobacco acetolactate syntase gene. Plant Physiol 132:174-184

Liao FL, Wang L, Yang LB, Zhang LY, Peng XB, Sun MX (2013) Antisense oligodeoxynucleotide inhibition as an alternative and convenient method for gene function analysis in pollen tubes. PLoS ONE 8:e59112

Liua WY, Chang YM (2013) Anatomical and transcriptional dynamics of maize embryonic leaves during seed germination. Proc Natl Acad Sci 110:3979-3984

Lusardi MC, Neuhausurl G, Potrykus I, Neuhaus G (1994) An approach towards genetically-engineered cell fate mapping in maize using the Lc gene as a visible marker-transactivation capacity of Lc vectors in differentiated maize cells and microinjection of Lc vectors into somatic embryos and shoot apical meristems. Plant J 5:571-582

Naim F, Dugdale B, Kleidon J, Brinin A, Shand K, Waterhouse P, Dale J (2018) Gene editing the phytoene desaturase alleles of Cavendish banana using CRISPR/Cas9. Transgenic Res 27:451-460

Nishitani C, Hirai N, Komori S, Wada M, Okada K, Osakabe K, Yamamoto T, Osakabe Y (2016) Efficient genome editing in apple using a CRISPR/Cas9 system. Sci Rep 6:31481

Odipio J, Alicai T, Ingelbrecht I, Nusinow DA, Bart R, Taylor NJ (2017) Efficient CRISPR/Cas9 genome editing of phytoene desaturase in cassava. Front Plant Sci 8:1780

Qin GJ, Gu HY, Ma LG, Peng YB, Deng XW, Chen ZL, Qu LJ (2007) Disruption of phytoene desaturase gene results in albino and dwarf phenotypes in Arabidopsis by impairing chlorophyll, carotenoid, and gibberellin biosynthesis. Cell Res 17:471-482

Rádi F, Török K, Nagymihály M, Kereszt A, Dudits D (2020) Improved reliability in production of maize inbred lines by the combination of the R1-navajo marker with flow cytometry or microsatellite genotyping. Cereal Res Commun 48:423-430

Rivera-Torres N, Kmiec EB (2016) Genetic spell-checking: gene editing using single-stranded DNA oligonucleotides. Plant Biotechnol J 14:463-470

Ruiter R, van den Brande I, Stals E, Delaure S, Cornelissen M, D'Halluin K (2003) Spontaneous mutation frequency in plants obscures the effect of chimeraplasty. Plant Mol Biol 53:675-689
Sauer NJ, Mozoruk J, Miller RB, Warburg ZJ, Walker KA, Beetham PR, Schopke CR, Gocal GFW (2016) Oligonucleotide-directed mutagenesis for precision gene editing. Plant Biotechnol J 14:496-502

Schindelin J, Arganda-Carreras I, Frise E, Kaynig V, Longair M, Pietzsch T, Preibisch S, Rueden C, Saalfeld S, Schmid B, Tinevez JY, White DJ, Hartenstein V, Eliceiri K, Tomancak P, Cardona A (2012) Fiji: an open-source platform for biological-image analysis. Nat Methods 9:676-682

Sticklen MB, Oraby HF (2005) Invited review: shoot apical meristem: a sustainable explant for genetic transformation of cereal crops. Vitro Cell Dev Biol Plant 41:187-200

Sun CX, Hoglund AS, Olsson H, Mangelsen E, Jansson C (2005) Antisense oligodeoxynucleotide inhibition as a potent strategy in plant biology: identification of SUSIBA2 as a transcriptional activator in plant sugar signalling. Plant J 44:128-138

Svitashev S, Young JK, Schwartz C, Gao H, Falco SC, Cigan AM (2015) Targeted mutagenesis, precise gene editing, and site-specific gene insertion in maize using Cas9 and guide RNA. Plant Physiol 169:931-945

Tang, X., G. Q. Liu, J. P. Zhou, Q. R. Ren, Q. You, L. Tian, X. H. Xin, Z. H. Zhong, B. L. Liu, X. L. Zheng, D. W. Zhang, A. Malzahn, Z. Y. Gong, Y. P. Qi, T. Zhang, and Y. Zhang. 2018. A largescale whole-genome sequencing analysis reveals highly specific genome editing by both Cas9 and Cpf1 (Cas12a) nucleases in rice. Genome Biol 19

Tiricz H, Nagy B, Ferenc G, Torok K, Nagy I, Dudits D, Ayaydin F (2018) Relaxed chromatin induced by histone deacetylase inhibitors improves the oligonucleotide-directed gene editing in plant cells. J Plant Res 131:179-189

Xie ZP, Sundstrom JF, Jin YK, Liu CL, Jansson C, Sun CX (2014) 'A selection strategy in plant transformation based on antisense oligodeoxynucleotide inhibition'. Plant J 77:954-961

Wang SH, Zhang SB, Wang WX, Xiong XY, Meng FR, Cui X (2015) Efficient targeted mutagenesis in potato by the CRISPR/Cas9 system. Plant Cell Rep 34:1473-1476

Wojtasik W, Kulma A, Boba A, Szopa J (2014) Oligonucleotide treatment causes flax beta-glucanase up-regulation via changes in gene-body methylation. BMC Plant Biol 14:261

Zhu T, Peterson DJ, Tagliani L, St Clair G, Baszczynski CL, Bowen B (1999) Targeted manipulation of maize genes in vivo using chimeric RNA/DNA oligonucleotides. Proc Natl Acad Sci USA 96:8768-8773

Zhu T, Mettenburg K, Peterson DJ, Tagliani L, Baszczynski CL (2000) Engineering herbicide-resistant maize using chimeric RNA/DNA oligonucleotides. Nat Biotechnol 18:555-558

Zhu JJ, Song N, Sun SL, Yang WL, Zhao HM, Song WB, Lai JS (2016) Efficiency and inheritance of targeted mutagenesis in maize using CRISPR-Cas9. J Genet Genom 43:25-36

Publisher's Note Springer Nature remains neutral with regard to jurisdictional claims in published maps and institutional affiliations. 


\section{Authors and Affiliations}

\section{Feríz Rádi ${ }^{1,2,3} \cdot$ Bettina Nagy $^{1,7}$. Györgyi Ferenc ${ }^{1}$ (D) Katalin Török ${ }^{1}$ István Nagy ${ }^{4,5} \cdot$ Zoltán Zombori $^{1}$. Dénes Dudits ${ }^{1,2} \cdot$ Ferhan Ayaydin $^{6,7}$}

Feríz Rádi

rferiz92@gmail.com

Bettina Nagy

nagy.bettina@brc.hu

Katalin Török

torok.karolyne@brc.hu

István Nagy

nagyi@baygen.hu; nagyi@atgandco.hu

Zoltán Zombori

zombori.zoltan@brc.hu

Dénes Dudits

dudits.denes@brc.hu

Ferhan Ayaydin

ayaydin.ferhan@brc.hu; ferhan.ayaydin@hcemm.eu
Institute of Plant Biology, Biological Research Centre, Eötvös Loránd Research Network, Szeged, Hungary

2 Kiskun Research Center Ltd, Kiskunhalas, Hungary

3 Doctoral School in Biology, Faculty of Science and Informatics, University of Szeged, Szeged, Hungary

4 Institute of Biochemistry, Biological Research Centre, Eötvös Loránd Research Network, Szeged, Hungary

5 ATGandCo Biotechnology Ltd, Mórahalom, Hungary

6 Hungarian Centre of Excellence for Molecular Medicine (HCMM) Nonprofit Ltd, Szeged, Hungary

7 Laboratory of Cellular Imaging, Biological Research Centre, Eötvös Loránd Research Network, Szeged, Hungary 